Research, part of a Special Feature on Law and Social-Ecological Resilience

\title{
The Capacity of Property Rights to Accommodate Social-Ecological Resilience
}

$\underline{\text { Richard A. Barnes }}^{1}$

\begin{abstract}
Here, I consider how social-ecological resilience can be facilitated by the use of property rights. Taking a legal perspective on the use of different forms of property, I consider how property rules can manifest the attributes of flexibility, responsiveness, optionality, and scalability associated with resilient systems. I note how different regulatory regimes such as domestic law and international law have differing capacities to accommodate property rights, and this in turn affects the capability of property to sustain resilience. The fluid nature of resilience and property systems defies simple conclusions about the influence of property rights on resilience. However, it is possible to make some general observations on how well-suited archetype forms of property such as private property and community-based holdings might be for regulating certain resources.
\end{abstract}

Key Words: community-based holdings; domestic law; environmental law; EU law; international law; natural resources; private property; property; resilience

\section{INTRODUCTION}

How best to manage dwindling, endangered, or finite resources in light of societies' expanding and changing demands is one the most important and difficult tasks facing us today. Because property rights define relationships between people in respect of things, and almost all things are subject to some form of property, the regulation of property has a fundamental role to play in the management of the world's resources. Viewed instrumentally, law is a tool for creating, defining, allocating, managing, and protecting property rights; it establishes rules and frameworks for deciding how to use things, including environmental goods and services. Although much has been written on the justification and operation of property rights, the literature remains underdeveloped in respect to developments in our understanding of environmental goods and services and complex phenomena such as ecosystems and biological diversity. In the last few decades, resilience scholarship has begun to provide new ways of thinking about the relationship between ecological systems and social systems, not as discreet systems, but as interlinked, symbiotic systems (Folke 2006). Recently, tentative steps have been taken to explore how thinking about resilience can be applied to thinking about law. Tarlock (1994) in particular has challenged how law can adapt to the idea of a nonequilibrium paradigm in which natural systems evolve continuously.

Here, I aim to contribute to the discussions about law and resilience by mapping out the relationship between socialecological resilience and the operation of property rights over natural resources. First, I consider the nature and scope of resilience scholarship. The aim is to draw out some of the key concepts that define resilience and that can be accommodated in legal institutions. Second, I make some observations on how law in general can facilitate resilience. Because law defines property rights, certain characteristics of law and legal reasoning, as well as the operation of legal institutions, will determine how property rights can facilitate social-ecological resilience. Of particular importance is the capacity of law (domestic, regional, and international) to manage property rights at different spatial scales. This is important because many social-ecological systems transcend individual States and domestic property regimes. Finally, I outline the structure and operation of property rights, focusing particularly on private property, and consider the extent to which property rights can either accommodate or impede social-ecological resilience. I argue that the rich diversity of property rights renders it a highly flexible institution, seemingly well-suited to facilitating social-ecological resilience, at least at local scales.

\section{SOME REFLECTIONS ON RESILIENCE}

The idea of resilience was developed by Holling (1973) as a way of explaining how natural systems tolerate stress and retain their basic functioning. Initially focusing on localized relations between species and habitats, prey and predator, the early approaches have since been refined, developed, and applied to more complex, larger-scale ecosystems. In a state of the literature review, Folke (2006) notes how the resilience perspective has since influenced social science research, especially in the fields of economics, human geography, and management. Recently, resilience thinking has started to permeate into legal scholarship and influence how we can understand the design of legal institutions (Ebbesson 2010).

Four concepts are central to understanding resilience: identity (or state), persistence, adaptation, and transformability. Identity comprises the variables that constitute the system. For example, a fish stock is measured in terms of its biomass within a particular marine space. A legal system may be defined by 
the rules, procedures, and institutions within a given jurisdiction. A system is persistent if it is able to withstand pressures and change. For example, a fish stock may respond to high levels of predation by increased spawning levels. A legal system's persistence might be measured in terms of its capacity to withstand internal legal challenge or external pressure for reform. The response to change or pressure describes the system's capacity to adapt. This is invariably quite contextual. Continuing with the example of a fish stock, its capacity to recover from overfishing will depend on a range of variables, including the size of the stock, species characteristics, availability of food and habitats, and competition from other species. Other variables such as the level of pollution, water temperature, and salinity may also come into play. It should be noted that the adaption of social systems tends to be the result of deliberative social processes. Thus, a legal system can adapt through legislative reform and dispute resolution. Transformability refers to the capacity of a system to change into a fundamentally new system when social, economic, political, or ecological conditions make the old system untenable (Walker et al. 2004). Transformation may occur naturally or it may be forced by changed environmental and/or social conditions. For example, transformation might include the designation of areas of ocean space as an offshore wind farm in place of fishing grounds, thereby prioritizing energy generation and potential habitat protection over fisheries. An apposite example of transformation of a social/legal system was the collapse of communist regimes in Europe and the emergence of marketbased systems favoring the use of private property rights-based approaches, rather than State-based command and control regulation.

Much research into resilience has focused on developing our understanding of what makes a system resilient, designing and understanding adaptation strategies, and evaluating the possibilities of and mechanisms for transforming systems. Initially, two approaches were dominant in the literature: engineering resilience and ecological resilience (Holling 1996). Engineering resilience focuses on keeping a system near a stable equilibrium or return to the equilibrium following a disturbance. It favors efficiency, constancy, and predictability in the design of systems. However, although this approach may well work in linear systems, it seems ill-suited to the complexity and unpredictability of systems in the real world, as the fisheries example described above shows. In contrast, ecological resilience is concerned with "the magnitude of disturbance that can be absorbed before the system changes its structure by changing the variables and processes that control behavior" (Gunderson and Holling 2002:28). More recently, appreciation of the complex interactions between natural and social systems has challenged us to think about the resilience of social-ecological systems rather than discreet natural and social systems. The point to note is that there are various strategies available to achieve resilience, with increased focus on system complexity.

Resilience commits us to dealing with complex systems, and this presents many challenges. Social-ecological systems in particular are characterized by complexity and nonlinear dynamics. This means we need to have regimes with the capacity to deal with uncertainty and surprise. We also know that the resilience of a system may depend on interactions and influences at different spatial scales. For example, changes in global climate can affect the ocean's salinity, which may have an effect on the dynamics of fish stocks and hence fishing patterns (Roessig et al. 2004). This requires an understanding of natural and social systems at multiple scales and further complicates the management of social-ecological systems. Both natural and social systems can withstand different kinds of pressure and respond in different ways, and may be predisposed to certain types of resilience and to certain types of management. We need to be able to evaluate which management strategies are best suited to each system. Because each system possesses different qualities and attracts different management objectives, it would seem that the use of resilience strategies will be highly contextual. Hence, resilience should not be regarded as an absolute constraint on action. Moreover, it is essential to recall that although ecosystems may be natural phenomena, they are still conceptualized by humans. This means that the parameters of any given system will be influenced by human values or preconceptions about how things work. This contingency may be a consequence of limits in knowledge, but is also the product of value-laden structures of knowledge. As already indicated, the selection of resilience strategies will often depend on what goals are perceived as socially desirable. Thus, high productive food capacity from agricultural land may be preferable to a high variety of food production so as to secure sufficiency of food supplies. In more abstract terms, do we desire more controlled systems at the risk of flexibility? There is no simple answer to this question; ultimately, resilience appears not to be a panacea. Rather, it provides useful ways of understanding how systems work, and this in turn helps us make choices about how we should manage these systems.

Although the foregoing presents a somewhat daunting set of challenges, there are some useful lessons that we can take forward into an analysis of property rights. Fundamentally, resilience is a knowledge-based approach. Knowledge underpins our understanding of the state of a system and its persistence. It also shapes adaption and transformability strategies. Although knowledge is often contingent or incomplete, because it underpins decision-making, resilience strategies should seek to enhance the production of knowledge. The capacity to generate and harness knowledge implies the existence of suitable social structures for managing systems. This is reinforced by the fact that adaption and transformation is generally accommodated through social 
intervention. This requires institutions with the capacity to define problems; determine goals and objectives for the management of a system; determine system parameters and baselines; develop conceptual models; select future restoration actions; implement and manage actions, monitoring systems, and responses; and evaluate activities (Ruhl 2011). If resilience is to be managed, then any decisionmaking process must possess a number of other attributes. First, because adaptation and transformation will be affected by the underlying quality of knowledge about a socialecological system, effective lines of communication and use of knowledge between stakeholders and management agencies may improve decision-making. Second, both adaptation and transformation require a management regime to be flexible to allow managers to respond to changes in a social-ecological system. Systems must be flexible, but within limits, because a high degree of flexibility may result in uncertainty and thereby undermine the ability of people to plan their conduct. Of course, adaption to change or transformation depends upon the possibility of change. The availability of management options will depend on the characteristics of a system, the creativity of management agencies, and management priorities. For example, a precarious system may have fewer options for recovery than a more stable system. Generally, a more resilient system will maintain more options for change or transformation. Thus, the third quality of resilient management is optionality. However, such a system will be more difficult to manage than a simple system with limited variables of change. This suggests that optionality will be limited by what is practical. Flexibility is also related to a fourth requirement of resilient management: responsiveness. A more adaptive system will generally be one that is responsive and able to implement measures more quickly. Whereas flexibility describes the capacity for change, responsiveness is a measure of the speed of change. Fifth, resilient management should ensure that decision makers have sufficient competence to adopt decision. This should include scope for autonomous decision-making because strongly hierarchical or complex procedures may impede decisionmaking by slowing down the speed of responses. Finally, given that the resilience of a system can be affected by changes at different scales, a management regime should be capable of operating a multiple scales so that account can be taken of changes systems at higher and lower levels.

In brief, we can analyze the capacity of property rights to accommodate resilience in terms of property's capacity to generate and harness knowledge, as well as the extent to which the rules governing property are flexible, responsive, maintain future options, and allow for regulation at appropriate scales.

\section{LAW AND RESILIENCE}

Because property rights are mediated through law, it is necessary to consider briefly the relationship between law and resilience because the inherent qualities of legal rules will necessarily influence the extent to which property rights can accommodate resilience. For example, open-textured rules or principles may provide greater scope for adapting to change than precise rules (Ebbesson 2010). I begin by considering how resilience can influence law, before noting how the general attributes of law as a concept appear well-suited to accommodating the features of resilience. However, the extent to which this is possible seems highly contingent upon the attributes of any given legal system's institutional structures and processes.

Resilience is both an analytical device and a normative value. It can be used to evaluate the effectiveness of law's capacity to regulate social and natural systems, and it can be part of the design goals for a legal system, set of legal institutions, or even rules. In both cases, this is no straightforward matter because, as noted above, resilience is not a singular approach. It is highly complex, contextual, and knowledge dependent, meaning that it does not provide an easy measure of the quality of a system, nor is it certain the meaning or weight to be afforded to resilience in any given system. It must be weighed against other values that legal systems seek to advance. For example, property rights are typically justified according to a range of values, including labor/desert, liberty, utility, efficiency, and propriety (Barnes 2009). Such values help determine whether any given form and allocation of property is desirable. There would appear to be space to include resilience alongside such well-established values. However, we must be cautious. Although resilience may be a quality of a social system, it does not necessarily make the system good (Ruhl 2011). Thus, a dictatorship may be a resilient form of government, but it is unlikely to be regarded as a good thing. On the other hand, the resilience of a legal system may provide a degree of certainty and hence the basis for security of expectations. In the same way that liberty or justice might be measures or goals of a legal system, we need to develop the meaning and content of resilience.

If law is to facilitate resilient social-ecological systems, then it ought to be able to display and nurture the attributes of resilience and adaptation. It should be flexible, responsive, and knowledge driven, maintain options, and possess effective governance mechanisms. In large part, the first four requirements can be accommodated by law because of its dynamic nature.

All legal systems comprise a complex mix of regulatory approaches: legislation and case law, procedural rules and substantive rules, formal laws and informal customs, broad guiding principles and particular rules. These are often combined with nonlegal mechanisms (e.g., economic policies and financial incentives) for achieving particular social goals. The choice of regulatory tool largely depends on the perceived optimal social outcome, but it should also suit the nature of the social-ecological system (Gunningham and Sinclair 2005). 
Certain regulatory approaches are better suited to certain resilience strategies. For example, at a general level, it may be observed that principles with their open, flexible application may be better suited to ecological resilience strategies, whereas rules of specific application may be better suited to engineering resilience. The point here is not to advocate in particular form of regulatory tool, but rather to note that most legal systems prefer a pluralist approach to regulation and retain a toolkit of measures to be used as appropriate. In short, most legal systems accommodate a range of regulatory options.

It is generally accepted that the process of legal reasoning, which helps determine the application of specific rules in specific contexts, requires legal assertions to possess certain attributes that make them compelling (Alexy 1989). Legal rules will stand or fall depending on both the context of the rule and the quality of the reasoning that underpins it. This requires rules to be reasonable and coherent and sensitive to legal and behavioral consequences (MacCormick 2005). The process of reasoning sustains a tension between certainty and flexibility and is central to the nature of law. Crucially, legal reasoning does not happen in the abstract, it happens within specific contexts. In this sense, law is open to development, it can accommodate a range of scenarios, and it is driven by reasoning processes that are predisposed to the harnessing of knowledge.

Law is an inherently iterative process that works through a tension between determinacy and adaptability (Ebbesson 2010). Although it is desirable that law is systematic and ordered, no legal system is complete and unchanging. Indeed, experience shows that absolute rules are but a short step from totalitarianism. Thus, it is a good thing for laws, rules, and principles to be constantly tested and exposed to critical scrutiny through public debate and legal challenge. When the values that underpin the law change, then the law must adapt. Moreover, rules do not cover every eventuality, and even if we could exercise divine foresight to regulate for all contingencies, then the indeterminacy of language presents yet another barrier to our desires for prescriptive certainty. Together, these factors cause law to possess a defeasible character. Defeasibility refers to a quality of rules that entails their defeat or qualification under certain conditions (Tur 2001). This generally happens when overriding reasons for not applying the normal rule arise. Defeasibility allows for the sequential development of basic propositions into far more complex rule structures. Through the iteration and recognition of qualifications or exceptions, law is capable of being calibrated to the complex realities of everyday life. This shows the propensity for legal rules to be both flexible and responsive.

Although law retains the potential to sustain the first four requirements of resilience, its capacity to do so may be enhanced or limited by the effectiveness of the institutions through which it operates. Institutions include formal bodies and structures such as legislatures and courts (institutional agencies), as well as arrangements and practices such as property. How then do the institutional capacities of different legal systems affect resilience? When referring to legal systems, we are not merely concerned with domestic law, despite the critical role it plays in regulating property rights. We are also concerned with regional regimes such as European Union (EU) law and international law. Social-ecological systems range from highly localized systems such as a farm or forest to global systems such as the atmosphere. Whereas localized social-ecological systems can often be accommodated exclusively within domestic legal regimes for regulatory and management purposes, many social-ecological systems extend beyond the limits of domestic jurisdiction. Because large-scale social-ecological systems cannot be regulated entirely under individual domestic legal systems (and sometimes regional systems, like EU law), international law plays a role in setting standards and harnessing cooperation between States. Accordingly, we must be aware of both the institutional qualities of these discreet legal systems and how they relate to each other because this can influence resilience and the operation of property rights. Institutional failings or structures can have consequences for the designation of control over resources and hence resilience. One wellobserved phenomenon is corruption, broadly understood as the misuse of public power for private gain. It can distort normal social interactions, embedding privileged and disadvantaged social structures, thereby undermining good governance. It may adversely affect resource protection by dislocating certain resources from formal protection or selectively exploiting vulnerable resources (Robbins 2000, Sundström 2012).

Both EU and domestic law possess strong vertically structured legal institutions capable of prescribing and enforcing legal rules. The existence of regularized legislative procedures and exclusive dispute settlement mechanisms points toward their capacity to engineer resilience by the creation of precise and binding rules. However, this is not necessarily at the expense of more ecological resilience strategies. Most legal systems, but particularly common law traditions, possess the capacity to respond to diverse situations through the courts. This can be done without fundamentally changing the structure of a system. For example, Ruhl (2011) notes how the law of nuisance, which concerns unlawful interference in others' enjoyment of their property rights, has adapted without compromising its basic principles or function in the legal system.

In contrast, international law is a horizontally structured legal regime based on the formal equality of States. It proceeds largely upon the basis of consent or consensus through a decentralized law creation processes and is principally 
concerned with the rights and duties of States. The absence of strong institutions makes it difficult for international law to establish tightly controlled regimes. Moreover, the emphasis on consent means that it tends to result in more open-textured or framework-type rules. This seems to predispose it toward ecological-type resilience strategies. To the extent that individuals are both part of the law creation process and subject to directly enforceable rights and duties, one expects domestic law, and to a lesser extent EU law, to be more socially responsive than international law. This is reinforced by the time it takes to produce law in these systems. The duration of domestic and EU legislative process is measured in terms of months and years, unlike international law, which is often measured in decades. Furthermore, most domestic legal systems have the capacity to adopt emergency or provisional measures to deal with unforeseen contingencies. The greater frequency of opportunities for the design, application, and testing of legal rules at local levels has produced much more carefully calibrated legal regimes. Accordingly, domestic and EU law retain a higher degree of sensitivity to shocks and change within the system. This means that projects aimed at the systemic integration of social and ecological systems are much further advanced than under international law. Examples include the EU Marine Strategy Framework Directive (MSFD) and the Marine and Coastal Access Act 2009 of England and Wales (MCAA). The MSFD aims to achieve "good environmental status" (GES) for European seas by 2020; to this end, Annex I contains a list of descriptors of GES that encompass both natural and social values. The MCCA requires the Marine Management Organisation to contribute to the development of sustainable development. More specifically, it requires a system of regionally based marine planning. This will structure the way in which a range of activities take place, both spatially and temporally in coastal waters, as well as facilitate the transboundary regulation of such activities. Both regimes are strongly reliant on a scientific knowledge base and advance flexible monitoring programmes capable of accommodating a wide range of marine conditions and activities at multiple scales. Moreover, both are being developed with a high degree of stakeholder engagement. The participatory and integrated processes inherent in these regimes renders them better suited to identifying and responding to changing social and natural conditions.

These regimes do not operate in isolation from international marine regulatory regimes, and there is some overlap here with the role of OSPAR, the regime for the protection of the marine environment of the North East Atlantic. OSPAR has done important work on the development of regulatory standards, including "ecological quality objectives" (EcoQOs). These are expressions of the structure and function of a system, including those resulting from human activities. They are linked to specific indicators and are used to establish management measures. This explicitly incorporates an ecosystem approach.
Interestingly, OSPAR regulations and monitoring systems will underpin some of the measures adopted under the MFSD or MCAA. This presents a more complex picture of how resilient domestic and international systems operate because they influence each other. However, from a formal legal point of view, it should be noted that OSPAR does not directly regulate individual conduct and hence property rights. In a UK context, OSPAR measures must be transposed through domestic law before they have effect. Also, although some of OSPAR's EcoQOs encompass natural resources, OSPAR's remit is more limited to pollution and protection of the marine environment. This means it cannot formally address key issues such as fisheries regulation, and so provides a less complete approach to the regulation of social-ecological systems.

Despite operating at different levels, domestic, EU, and international law are not isolated legal systems. Here is not the place to explore in detail the relationship between these legal orders. However, it is useful to provide some brief remarks on how different legal systems (domestic law, EU law, and international law) can shape property systems. It is important to appreciate that these mechanisms exist, because they provide the means for ensuring that impacts on and changes in social-ecological systems at global scales can feed into the regulation of systems at local levels. One general observation is that there may be a gap between the formal operation of legal institutional and actual practice. For example, States may have formal authority to regulate coastal fisheries, hence removing them from the common pool. However, if the State lacks the financial or institutional capacity to implement laws, then the fishery remains de facto open access.

As noted above, property is a private law institution, meaning that property rules will be located almost exclusively within domestic legal systems. There are perhaps four principal exceptions to the domesticity of private law institutions. First, certain substantive principles of international law are directly concerned with ensuring the proper use of natural resources, and this entails restrictions on the use of property within domestic law. Thus, States are required to ensure that activities within their jurisdiction do not cause harm outside their territories. There are also duties of notification and consultation, and commitments to carry out environmental impact assessments. Such duties require limits to be applied to private property rights under domestic law. Second, because certain areas remain beyond the exclusive jurisdiction of States, international law plays a primary role in regulating the activities of private persons in such international areas. Unless domestic legal regimes are extended to such areas or the resource therein, and this seems politically unlikely, then the only other option is for international law to establish rules applicable to private persons in such spaces. For example, the deep seabed has been designated the common heritage of mankind, a regime akin to common property with reasonably 
detailed rules on access to and use of mineral resources. The designation under international law of property rights over other resources such as fisheries is not straightforward and remains an emerging field of research (Barnes 2010). Third, international human rights law demands that property rules are compatible with fundamental human rights considerations, including the protection of the environment. Both domestic courts and international courts such as the European Court of Human Rights (ECHR) and the Inter-American Court of Human Rights have sought to ensure that the use of property is consistent with basic human rights, including the protection of the environment (Barnes 2009). For example, in Hamer vs. Belgium, the ECHR reaffirmed Belgium's right to demolish a house built on forestry land in breach of Belgian law designed to protect the environment, and the owner was required by the state to restitute the land to its previous state. The ECHR upheld the legality of Belgium's action, despite the impact on upon property rights. This protection of human rights is particularly important in the context of indigenous rights, where control of property may be vested in communities and is often associated with a strong ethic of environmental responsibility (Gilbert 2006). Thus, in Mayagna (Sumo) Awas Tingni Community vs. Nicaragua, the Inter-American Commission on Human Rights upheld a claim against Nicaragua for failing to protect communal land rights of an indigenous group by granting commercial logging concessions to private companies. Fourth, international investment law has begun to develop rules concerning the fair and equitable treatment of investments and hence property rights (Montt 2009). Although the precise level and standards of control on property rights through investment law is very much a live debate, it remains a relevant consideration.

To summarize, because law shapes property, the resilience of law will influence the resilience of property rights. The institutional qualities of international, EU, and domestic law affect the precise way in which law can accommodate resilience. Because international law operates at a global scale, it is better suited to dealing with the regulation of transboundary social-ecological systems such as the marine environment. It is highly flexible and adopts a wide variety of regulatory strategies to address social and environmental needs. However, because international law is concerned primarily with the rights and duties of States, it is generally ill-suited to the direct regulation of property. It may, however, exert indirect influence on the construction of property rights through its rules and principles governing the use of natural resources. Domestic law and EU law are more formalized and capable of developing precise and tightly controlled legal regimes. However, they also maintain a wide variety of regulatory strategies to deal with environmental issues. Given that domestic law directly sustains the institution of property, its governance structures will be of primary importance in facilitating social-ecological resilience strategies within property law.

\section{PROPERTY RIGHTS AND RESILIENCE}

In law, property rights concern the legal relationship between people in respect of things. A property right entitles the right holder to make a claim on an act or forbearance of another party in respect of a thing. This right has the force of domestic law behind it. Domestic law also ensures that the holders exercise their rights in accordance with any legal limits imposed upon the right. Property is not a monolithic concept. Neither does property operate in the same way in all domestic legal systems. The construction and operation of property rights is highly contextual, being the product a complex interplay of social, economic, and moral values over the course of history (Barnes 2009). However, some general, if somewhat abstract, observations can be made about the nature of property. It may be broken down into component legal relationships, including possession, use, management, income rights, transmissibility, security rights, as well as duties such as nonharmful use (Honore 1961). The ability of law to vary the quality of these incidents of ownership, and to allocate them among different persons, means that property in general is a highly flexible institution and, in principle, can sustain resilience strategies. However, I should also note that central to property is the idea of excludability, that is, the right to exclude others from a thing and determine how a thing should be used. Accordingly, the designation of property rights turns on whether or not something can be subject to exclusion. It is notable that many important resources remain outside institutions of property or subject to particular forms of property because they cannot be made excludable (Barnes 2009). This indicates limits to the extent that property or certain forms of property can compose part of a toolkit of techniques to facilitate resilience.

Traditionally, the objects of property rights have tended to be individual things that can be physically ascertained and/or commodified. As a result, the idea that natural resources constitute some discreet system or form part of a socioeconomic system has not featured in the design of property rights until recently. Of course, land holdings might encompass a socioeconomic system, but this has been somewhat incidental to the designation of land ownership. Rather, socioeconomic factors such as feudalism, farming and land-use schemes, and inheritance have been determinative of both the extent and allocation of holdings. Accordingly, the boundaries and content of land ownership rights have been drawn regardless of how they cut across natural systems.

However, in the last few decades, there has been increasing concern with the alignment of property rights and natural systems. This tends to operate through external constraints on property because it is difficult to accommodate positive environmental duties within existing rights. Planning regimes are increasingly focused on the consequences of developments on the wider environment. For example, British planning law requires development decisions to be made in accordance with 
a planning authority's development plan. This plan must be drawn up in accordance with national planning policy, which establishes a presumption in favor of sustainable development and specifically requires that certain environmental considerations form part of the development control process (Department for Communities and Local Government 2012). The effect of this is to subject property rights (such as an owner's right to build on land) to control, in light of the wider impacts of such a development on the environment. This proactively and prospectively shapes the way in which property and land can be used. Similarly, Article 10 of the EU Habitats Directive requires Member States to "endeavour, where they consider it necessary, in their land-use planning and development policies and, in particular, with a view to improving the ecological coherence of the Natura 2000 network, to encourage the management of features of the landscape which are of major importance for wild fauna and flora." Although phased in hortatory terms, the requirement has been implemented under British law in more demanding terms by Regulation 39 of the Habitats Regulations 2010. This defines policies relating to land use and development under planning legislation as including policies for the protection of habitats, thereby making habitat considerations a central part of statutory planning control. This requires consideration not merely of designated protected sites, but also of corridors and other natural features that connect designated sites.

Given this interest in aligning natural and social systems, how then can property rights facilitate resilience? The answer to this seems to depend, first, on how desirable a goal resilience is for society, and second, on which form of property is used to facilitate this goal.

Although property is often regarded as a private right, it provides an important public function (Barnes 2009). Property is consciously designed to maintain a proper form of social order. It is an institution of a community, and so first and foremost, it is designed to meet certain core community values. Typically, these include guaranteeing that basic human needs can be met, and securing a basis for planning future activities. This general point about community values and the public function of property is crucial because it suggests that community interests are as important as private interests when it comes to defining individual property rights. This public or social dimension of property helps explain why property rights vary between different legal systems. For example, water rights may vary considerably from country to country (Hodgson 2006). Such differences also arise in respect of land, mineral deposits, and forests (McHarg et al. 2010). It is no surprise that such differences arise in the context of key natural resources, given the strong public interest in their allocation and use.

Resilience seems to fit with the idea of a public good because it is concerned with the desirability and durability of social- ecological systems. If resilience is categorized as a public good, or indeed a desirable form of order, then it can be used to define the public limits or even private responsibilities of property owners. Of course, this approach is predicated on whether or not the resilience of certain natural or social systems is "good", and, as noted above, this may be contentious. However, even if this point about the general desirability of resilience is contested, a strong argument can still be made that social-ecological facts remain a constraining aspect of property. This is because property rights should be drawn in line with the essential qualities of the thing to which they apply. For example, riparian rights must acknowledge the fluid nature of water and its interactions with the wider environment. Such facts not only comprise physical limits of things, but also alert us to the interconnectedness of the individual components of a system such as the relationship between prey and predator, and the nature of food chains. That property comprises a series of legal relations between people in respect of things should not disguise the fact that the physical attributes of a resource are in many ways determinative of the legal relations that govern its use. Thus, air is free of private property because it would be both practically impossible to bound it and morally objectionable to seek to exclude persons from an essential good. In this sense, resilience, which provides a framework for understanding natural and social systems, is a device that demands and enables us to consider closely the relationship between things and rules and to account for the real world consequences of establishing particular forms of property.

Property regimes generally combine a number of types of property, ranging from individual private property to forms of collective holding. Indeed, the range of property holdings varies incredibly, depending on how the various incidents of ownership are designed and allocated. This reaffirms the inherent flexibility of property and opens up possibilities for quite varied and adaptable forms of property. The variable attributes of property mean that it can provide quite different levels of support for (or impediment to) social-ecological resilience. It is not possible to survey every type of property, so I consider some archetypes: private property and community based holdings (CBHs). Before outlining these two types, I want to make clear my position: no single type of property is a panacea. There is much debate about whether privatization is a solution for problems of environmental degradation, particularly for global commons (Ostrom 1990). However, it seems intuitive, given the wide range of and quality of things and the complexities of social organization, that there can be no one-size-fits-all solution. Experience and the variety of property regimes we have in practice seem to prove that a plurality of property structures is necessary. This much is also consistent with the general requirement of optionality, although, as noted below, the availability of certain options may be limited because of social and legal 
pressures embedded within particular arrangements of private property.

\section{Private property}

A system of private property vests rights of exclusive control over a thing in the hands of a single person. Private property is a widespread and enduring form of property and may be regarded as socially resilient. In recent years, novel forms of private property, like transferable environmental allowances (TEA), have been developed to bring to bear some of the positive attributes of property on environmental problems. A TEA is created when the state establishes a cap on the quantity of a resource that may be used. The available resource may then be divided into individual allowances and shared out among a limited group of "owners", and other potential users are excluded from the regime. The TEA may be bought, sold, used, and otherwise treated like private property, at least to the extent that the regulatory regime permits. It is the ability of the regulatory regime to capture these attributes of private property that make TEAs desirable management tools. Such entitlements have been developed for a range of resource regimes, including fisheries and emissions trading schemes, suggesting that private property is a rather adaptable institution. The question is, then, how far can private property accommodate the attributes of social-ecological resilience identified above: the generation of knowledge, flexibility, responsiveness, optionality, and scalability associated with resilience?

We can begin by noting that private property seems designed to secure the continued existence of the objects of property. Most justifications for private property attach considerable weight to the fact that the owner has a vested interest in preserving the capital of his/her holding. Because the owner of a thing enjoys all the benefits of a thing, assuming him/her to be rational, he/she will not do something that diminishes its value through destructive or wasteful use. Thus, we look after our homes and cultivate our land, and most legal regimes have developed duties of nonharmful use of property to reinforce this. Here, there seems to be a natural alignment of private property rights with some notion of persistence. However, this is only part of the picture because resilience is about more than maintaining the existence of individual things; it is about the resilience of the social-ecological system. This presents some particular challenges for private property.

Because private property rights are generally individual claims against the wider community and often the State, they require strong institutional support under domestic law. As such, private property is strongly tied to both the robustness of the domestic legal system and the values that the legal system embodies. This may result in inflexible property regimes because the emphasis in most private property regimes is on guaranteeing security of expectations. However, the existence of strong private property rights may have positive consequences for resilience. For example, most planning regimes have developed sophisticated procedures that allow for the mediation of private development concerns and public interests. Also, the law of nuisance can be used to protect property from the harmful actions of other property owners. In some circumstances, private law actions can be used to challenge or expedite public decisions concerning the use of property (McGillivray and Wightman 1997). If successful, this can provide a check on imperfect regulatory regimes; even if unsuccessful, it can help to ensure debate, increase awareness of issues, and put pressure on regulators (Bishop and Jenkins 2011). It thereby serves to ensure that decision-making is more pluralistic, socially responsive, and knowledge driven. For example, in Massachusetts vs. EPA (549 U.S. 497 [2007]), the U.S. Supreme Court remanded a decision back to the Environmental Protection Agency because it had failed without reason to exercise its authority to establish measures to control greenhouse gas emissions from motor vehicles under the Clean Air Act. Here, a public nuisance action was brought against a public body that was perceived to have failed in its duty to regulate private property in a way that limited certain harmful consequences. Of course, such judicial intervention is not the usual device for deciding how property should be regulated in complex systems, and the courts are more often reluctant to interfere with duly constituted administrative procedures for regulating property and protecting the environment. Thus, in a more recent U.S. Supreme Court case, American Electric Power vs. Connecticut (131 S.Ct. 2527 [2011]), it was held that a statutory regime for emissions control had displaced a common law nuisance action. The underlying rationale in this case appears to be that if a complex regulatory matter has been entrusted to an administrative body, then the courts should not interfere in how this power is exercised. As the court stated in American Electric Power, "Federal judges lack the scientific, economic, and technological resources an agency can utilize in coping with issues of this order." This refrain from intervening in a question of resource management indicates that there are limits on how far judicial mechanisms can be used to deal with complex social-ecological systems.

As noted above, private property rights, and TEAs in particular, have tended to apply to single components of socialecological systems, rather than the entire system. Thus, the global atmosphere is a global commons and subject to collective management by States. As such, no individual has an "owner's" interest in preventing harmful activities from degrading the atmosphere. This suggests that there are potential limits to the capacity of private property to facilitate resilience in large-scale systems. There are both strong moral grounds for retaining nonexclusive interests in systems such as the atmosphere, and practical difficulties in designating a single authority to control a resource that wraps the entire world and the multitude of States and communities therein. 
Such practical limits tend to flow from structural limits inherent in private property. Morally, it would be questionable to vest exclusive control over fundamentally important things to a single person or agency that could determine access and use, and potentially deprive people of access to essential goods. In practical terms, there are problems in securing exclusive rights over a global system.

The global atmosphere might be an extreme example of a nonexcludable social-ecological system, but such practical questions about the relevance and application of private property remain at smaller scales; hence, the general absence of ownership of marine resources or habitats. These limitations flow from structural requirements inherent in private property. First, private property rights generally need to be quite simple because this facilitates both their security and tradability (Rose 2002). If the precise scope of the right is ill-defined or is subject to considerable external regulation, then the value and function of the right is reduced, and individuals cannot plan for the future. Our understanding of the boundaries and nature of complex large-scale systems is limited, and this makes it difficult to even draw the boundaries of any potential private property right. Second, private property needs to be supported by a single legal system capable of defining, regulating, and enforcing the right; for transboundary resources, this is not possible under domestic law. Such concerns indicate that private property may not be suitable for the regulation of large systems as a whole.

This is not to deny that private property rights can operate at larger scales or apply to the components of large socialecological systems. One of the advantages of private property is that transactions can readily take place between strangers because property rules are usually quite simple and wellunderstood (Merrill and Smith 2000). This means that private property can operate at quite large scales, facilitating transactions across State borders and forming part of a global regulatory regime. Clearly, forms of private property do operate at global scales, allowing international trade in commodities, global stock markets, and TEAs in the form of tradable emissions quotas and fishing quotas. However, such rights relate to components of systems, rather than whole systems. As such, they provide only part of a regulatory response to resilience. Even then, private property may run into difficulties because individual property transactions at these scales can generate high transaction costs and externalities. For highly complex social-ecological systems with multiple ownership interests in individual components of the system, the time and cost of negotiating a management regime to account for system-wide concerns is likely to be prohibitive. This is apparent if we look at the example of rightsbased fishing entitlements. These only pertain to the fish, and not the wider marine ecosystem. Because such rights are limited to specific species, this tends to increase the potential difficulties arising from externalities such as by-catches, discards, and adverse impacts of fishing techniques on the marine environment. Ultimately, any fisheries management regime using TEAs must still deal with externalities. In practice, this is likely to require considerable regulatory intervention or a profound restructuring of the individual rights. This may then defeat the advantages of using private property in the first place.

Such problems are even more acute with respect to efforts to manage biodiversity. Biodiversity is defined as the variability within and between species and their ecosystems. As such, it is a nonexclusive interest that transcends the individual components of biodiversity (which may or may not be owned). The conservation of biodiversity requires not merely limits on the use of resources, but positive obligations to cooperate so that knowledge of systems and their use is shared. However, such cooperative requirements seem to comprise duties, and this seems difficult to accommodate within a concept of private property built around exclusive claim rights in specific resources (Barnes 2010). It may be possible to accommodate positive duties of cooperation into property holdings, but this would seem to require appropriate incentives to holders of the right to act in a particular way, or some restructuring of the right to manage a thing, for example, by vesting part of this in an external agency that can compel cooperation. However, at this point, the nature of the holding has fundamentally changed from private property to something else like stewardship of collective property.

Forms of private property can be varied to accommodate a wide range of circumstances, thereby meeting the need for flexibility in resilient systems. Because private property rights are bundles of rights, they can, in theory, be divided and allocated in many different ways. Thus, a proprietary interest in farmland is defined quite differently to a proprietary interest in an emissions permit. The former might have an open-ended duration and include extensive rights of use and management, whereas the latter may only last for a period of years and be absent any management authority such as the right to decide overall emissions levels or monitoring and reporting requirements. Flexibility to adapt the form of holding, for example, by leasing the property or sub-dividing it, is a highly desirable attribute and shows how private property can be creatively developed and flexible in its application. It also indicates that property systems are inherently capable of meeting a diverse range of scenarios, and so contribute to optionality. Of course, whether or not individual forms of property are designed or adapted to meet changing circumstances will depend on the degree to which the owners interests are aligned with the change and the effectiveness of the institutional rules for property in securing change, either through the voluntary acts of the owner or the imposition of external constraints by the State.

As noted above, an owner has an exclusive interest in capital of his/her property. From a resilience perspective, a potentially 
negative side effect of this is that it may instill a desire to strengthen the right because this will increase the value of the holding. Thus, there is a tendency for private property regimes to consolidate the quality of the holding by securing greater control to the owner over rights to manage, use, and alienate a thing, and to extend the duration of such rights and protect against external interference, particularly from the State. If this happens, the private property right may become resistant to change because the State has less authority to interfere in a private right or determine how it can be exercised. This tension between secure private property rights and regulatory control is a feature of the debate over the creation of TEAs in fisheries. It is notable that the United States was extremely cautious about designating property rights over fisheries precisely because of the risk that constitutionally enshrined protections against regulatory takings would render fisheries management impossible or expensive (Barnes 2009). Such difficulties are likely to be even more profound when the transformation of a property regime is considered. Social resistance to the restructuring of property rights was widespread in Iceland and New Zealand when those countries introduced TEAs in fisheries (Barnes 2009). This shows how private property might result in engineered solutions, whereby certain social (i.e., private property) interests become entrenched within a legal system and are resistant to change.

Owners of private property respond in different ways and degrees to social and natural changes. Their potential resistance to regulatory intervention aside, there is a general consensus that property rights support social responsiveness. In a system of private property, authority to make decisions is highly decentralized, at least in the absence of a monopoly control of a thing or market. In such cases, the monopoly authority can strongly resist external regulation or market forces to protect its own interests, and it is notable that most legal systems have strong anti-monopoly laws to prevent such occurrences. In normal circumstances, private property creates the space for the exercise of choice and so frees owners to deal with their property in light of changing social or economic conditions. This is partially a function of the laws of supply and demand, and partially a manifestation of the emphasis on individual liberty in liberal societies. In theory, markets provide an efficient and responsive means of transacting (Farber 1994). Indeed, if the market is functioning properly, it can provide a means of ensuring that changed social conditions are met through changes to the allocation, structure, and value of property rights. In turn, this may reinforce the resilience of private property because it facilitates the pursuit of owner's goals. On the other hand, because private property can inculcate habituated decision-making by establishing a domain free from external influence, it may become unresponsive. Rational people may be reluctant to change the status quo, even when the benefits of change are known to outweigh the costs (Rachlinski 2000). For example, we are all culpable of putting lights on, letting taps run, or leaving the air conditioning running, even if not necessary and even if we know it may result in harm or waste. The point is not that property generates particular habits of waste or harm, but rather that the sphere of exclusive interest may limit external stimuli that can provoke behavioral changes and adaptation. Related to this is the difficulty of coordinating changes in behavior in a decentralized system of authority. Localized changes may happen organically, and changed behavior can evolve over longer time frames. However, this seems ill-suited to dealing with system-wide shocks or unforeseen changes such as natural disasters. These may require more immediate responses and generally depend upon regulatory intervention, which again may be resisted. Unless interference is justified and compensated, then we must be attuned to the potential resistance to change inherent in private property (Michelman 1967).

As a final point on the responsiveness of private property, there is the unresolved issue of how to take into account the interests of future generations when defining or regulating private property. Social-ecological systems are dynamic, so any resilience strategy (or transformation strategy) should account for future interests. Under a system of private property, this is not easily achieved because the decision-making authority is vested in actors with a limited knowledge of and concern for the circumstances of future generations. Intergenerational issues generally require some external agency capable of acting on behalf of future generations, and this is not generally an internal feature of private property regimes.

The extent to which private property rights facilitate and harness knowledge is rather complicated. Because the owner is normally guaranteed the fruits of any investment he/she makes in the property, he/she is encouraged to enhance and develop the resource. Thus, private property is seen to stimulate creativity and investment, and this may serve to generate knowledge about the property and enhance our understanding of the wider social-ecological system. Private property rights may be transacted in markets, and this encourages the gathering, development, and use of information because this information strengthens agents' chances of transacting to a beneficial outcome. In a free market, property transactions are undertaken on a voluntary basis and will be negotiated to accommodate as far as possible needs, interests, and expectations of both parties (Ellickson 1973). This process generates its own knowledge about practices, expectations, and desires, and underpins the operation of markets. However, at the same time, such knowledge may have commercial value, and there is no guarantee that knowledge about things will be disseminated. Indeed, this limiting of access to knowledge is the whole point about granting exclusive intellectual property rights over the results of certain activities like pharmaceutical research. 
Running through this review of private property and resilience is the idea that private property interests are not always aligned with resilience strategies. Positive alignment may arise incidentally from the owner's interest in the capital of the resource. For example, a landowner facing a loss of productive arable land due to desertification may be inclined to support a range of measures designed to mitigate the impacts of global warming or accept a proposed transformation of the land-use scenario. However, the alignment of interests cannot be assumed, and there will frequently be a conflict between individual interests and collective goals designed to adapt to changes in social-ecological systems. For example, adaptation to climate change may require the closure of a facility that contributes to the production of greenhouse gases or the sacrifice of land threatened by coastal erosion. In such cases, collective decisions will certainly be resisted by individual property rights holders. This suggests that a key challenge for management strategies based on private property is to align the interests of individual owners with the requirements secure social-ecological resilience.

\section{Community-based holdings}

Community-based holding (CBH) refers to a range of decentralized management regimes used to govern commonpool resources. My point is not to review and advocate such forms, but to explore how some of the general attributes of CBHs can accommodate social-ecological resilience. $\mathrm{CBHs}$ have been adopted for a range of natural resources systems, including fisheries, forests, pastures, and waterways (Ostrom 1990). There is a growing body of literature that shows the long pedigree of such regimes, and they certainly predate many modern private property-based regimes. As such, $\mathrm{CBHs}$ can be regarded as a resilient, or at least persistent, form of social organization. Because CBHs can operate on the basis of informal customs and practices, they may exist outside usual domestic property regimes. Indeed, the fact that such regimes do not necessarily require formal legal support suggests that they may be more resilient than private property, which is contingent on strong institutional support. However, although there is evidence of CBHs that have existed for hundreds of years without formal support by the State, in the longer term, some formal recognition of a CBH is likely to ensure its continuity (Berkes 1996). Some students of property might take the view that, ultimately, CBHs will be reduced to private or public property regimes as resource use intensifies and the externalities of common property begin to outgrow those associated with operating a system of private property. Notably, New Zealand kills two birds with one stone by using a system of private property-based fishing rights to remove inefficiency from marine commercial fisheries and capture indigenous fishing rights (Barnes 2009). However, recent regulatory developments in the field of environmental law appear to be challenging the apparent decline of $\mathrm{CBH}$. A key feature of $\mathrm{CBH}$ is the community involvement in decision- making. Arguably, public law requirements of participatory decision-making are reinvesting the regulation of land and other natural resources with a strong community element (Holder 2004). Although this might not challenge the fundament status of a thing as private property, by affording interested or affected persons with the right to be involved in decisions concerning the use of property, a degree of community-based management is re-engaged.

There is evidence that the effectiveness of CBHs is threatened when external circumstances generate pressure from nonmembers to alter the regime (Rose 2002). This can result from political changes such as those that occurred during the colonization of land by European States, or changes in environmental conditions such as famine or flood. This indicates that although CBHs can rely on internal management strategies to regulate resources, members of the defined user group still depend on external exclusion for the regime to work (Berkes 1996). As such, there are some similarities with private property-based regimes. Indeed, ultimately, exclusion of nonmembers of a community may require the same level and kind of formal support that private property rights require.

In principle, $\mathrm{CBHs}$ are as flexible as private property. Thus, $\mathrm{CBHs}$ range from the simple set of rules a village has developed to control grazing on common land to the far more complex arrangements based on kinship, locality, seasonal variations, and changing weather patterns that characterize some artisanal fisheries (Wilson et al. 1994). As in the case of private property, $\mathrm{CBH}$ can be structured to suit a wide range of social and natural circumstances and so is a potentially flexible management tool. However, this only describes the variety achieved through having a range of CBHs. It does not relate to the internal flexibility of individual CBHs. The latter will very much depend on the design of the individual $\mathrm{CBH}$.

A key feature of CBH is that it can be supported by both legal and extra-legal norms. The latter can be illustrated by India's formalization of a system of community-based ownership of forests by way of legislation, i.e., the Scheduled Tribes and other Forest Dwellers (Recognition of Forest Rights) Act 2006, which was designed to secure pre-existing but disparate rights associated with ownership of forest land and resources. At the level of international law, fisheries within the remit of a Regional Fisheries Management Organization are effectively a form of common property, even if international law does not designate this status to such fish stocks. Informal $\mathrm{CBH}$ can be illustrated by reference to numerous small-scale fisheries. For example, Acheson (2003) has done much to elevate the informal control of lobster fishing in Maine. Elsewhere, Bernstein (1992) has shown how community-based arbitration (in place of formal State based law) has helped the sustain diamond industry. Although not strictly a form of community property, the latter study indicates how informal community institutions can flourish, even in market-based contexts. 
This flexibility in the constitution of $\mathrm{CBH}$ means that it may be responsive to a wider range of values than are purely captured within a legal system. Indeed, CBHs are usually contingent upon adherence to norms, including trust, reputation, reciprocity, community pressure, and the pull of collective values. This may mean that $\mathrm{CBHs}$ can be socially responsive because, at least initially, they need to align resource use rules with a broader range of community needs. Of course, this also means that such regimes are most effective when the community values and processes are well defined and well settled. However, if a community lacks inclusive decision-making processes, then there is a risk that the $\mathrm{CBHs}$ can undermine wider social needs. Rose (2002) suggests that $\mathrm{CBHs}$ tend to become less socially responsive than private property regimes after they are fully established. This is because the complexities of the governance mechanisms that evolve over time are difficult to deconstruct. Also, ties of kinship or other social practices may render it difficult to leave or enter a regime and may preclude external social values from shaping the use of the property. This may be positive if it helps resist destructive consumptive demands such as consumerism, but it can equally result in the ossification of poor management practices.

It appears that CBHs may be more responsive to shifts in the natural environment than are property rights. $\mathrm{CBHs}$ often develop from customs and practices that reflect natural resource patterns such as the abundance of resources in particular places or at particular times. As the CBH develops, it adapts to identifiable patterns in the resource system, and this influences social practices. For example, rights to use water for irrigation in a $\mathrm{CBH}$ will be determined according to seasonal water levels (Ostrom 1990). This adaption is possible because individual entitlements are not as fixed as for typical private property rights. Moreover, decisions on use are taken in light of community needs, and these tend to prioritize the sustainability of the resource base.

The existence of a community is crucial to CBHs because this provides the structure for and values that define the management of the relevant resource. This has implications for the capacity of CBHs to operate at larger scales. Welldefined and structured communities tend to exist at local levels, where there are frequent interactions between users and opportunities to develop community values and practices. Accordingly, most CBHs operate at small scales (Rose 2002). Thus, fishing communities may be based around fishing towns and provide a basis for regulating local fisheries (McCay 2011). Here, I note that CBHs are less well suited to international resource regimes simply because the community structures and values are poorly developed at this scale. International law recognizes a number of international commons such as the high seas, deep seabed, Antarctic, and outer space, and such areas are regulated in a nonexclusive fashion, similar to CBHs. However, the absence of strong shared values and interactions between the heterogeneous groups of States comprising the international community has resulted in either weak or basic management regimes for these areas (Barnes 2010). Ostrom (1990) has suggested that CBHs can become nested and so operate at a larger scale. However, such coordination tends to require some degree of extracommunity-based support, usually though governmental institutions. So even if social-ecological systems are identified for coordination of $\mathrm{CBH}$ at the transnational level, the same structural problems inherent in the international legal system undermine the coordination or use of CBHs.

Finally, we can observe how CBH might facilitate knowledge. Because CBHs are community based, they naturally include a wider range of participants in the management process. Multiple stakeholders will be able to feed their experience into the management regime. It may be noted that McCay (2011), in the context of fisheries management, refers to epistemic communities based around expertise and shared concerns and values. Furthermore, the closed nature of the communitybased model will require participants to develop their practices mutually, rather than seek external solutions. These factors may enhance the role of knowledge within the system.

\section{CONCLUSION}

Social-ecological resilience has become a relatively wellunderstood concept, and it is increasingly used to influence the design of resource management regimes. As such, it will increasingly affect the design and operation of property rights over natural resources. Because property rights are sustained through legal rules and systems, property is necessarily infused with the broader values underpinning the legal system. Most legal systems have developed property rights according to long-established notions of desert, liberty, utility, and propriety, but they also require that property systems fit with the objects of property. This and the value inclusiveness of legal regimes suggest that there is plenty of scope to accommodate resilience within property institutions. However, the relative nature and contingency of resilience means that it will only be one among several values that influence the design and operation of property regimes. There seems little reason to doubt that property rights can accommodate social-ecological resilience. The defeasible and dynamic nature of law lends itself particularly to adaption. There is also a high degree of flexibility within domestic property systems, and, in principle, the great variety of property rights and their contextual application maintains the options necessary for resilience. Of course, particular configurations of property may be more of less suited to the regulation of particular resources or resource systems. The wide range and variability of both TEAs and CBHs makes it impossible to generalize about which form of holding is better suited to accommodating social-ecological resilience. Indeed, it may be that resource regimes require a combination of both; hence, legislation should be adopted that establishes forms of 
property or property management that capture elements of private property and CBHs. Complex combinations of private and community property can coexist in the same resource regime (Smith 2000). Ultimately, as Fennel (2011) notes, the issue comes down to a question of how best to accommodate multiple uses of things at different scale or different times. This perhaps accounts for the way in which property in the same resource evolves through different forms over time, and requires us to be flexible in our choice of property instruments.

Although the operation of property is more complex than this somewhat binary presentation of private property and $\mathrm{CBH}$ might suggest, some general observations can be still be offered on the capacity of different forms of property to accommodate social-ecological resilience. Private property is an enduring institution, capable of operating at large scales through market-based economies. Markets generally mean that private property is socially responsive, although it is important to appreciate that there are occasions when it can be very resistant to change. It is best suited to narrowly drawn resources, rather than large complex resource systems, and it encourages protection of and investment in resources. In contrast, CBHs may be better suited to complex resource regimes at local levels. Although less socially adaptive, they may be better suited to changes in ecological systems because of their greater sensitivity to the natural constraints on resource use. The capacity of either type of property will depend on the precise arrangement of resource use rules. As such, much more research into the practice of various property regimes and their impacts on social-ecological systems is required if we are to understand how well suited TEAs and $\mathrm{CBHs}$ are to accommodate social-ecological resilience.

Responses to this article can be read online at:

http://www.ecologyandsociety.org/issues/responses. php/5292

\section{Acknowledgments:}

My thanks to Jonas Ebbesson and Ellen Hey for their helpful insights and suggestions.

\section{LITERATURE CITED}

Acheson, J. M. 2003. Capturing the commons: devising institutions to manage the Maine lobster industry. University Press of New England, Hanover, New Hampshire, USA.

Alexy, R. 1989. A theory of legal argumentation: the theory of rational discourse as theory of legal justification. Clarendon Press, Oxford, UK.

Barnes, R. 2009. Property rights and natural resources. Hart, Oxford, UK.
Barnes, R. 2010. Entitlement to marine living resources in areas beyond national jurisdiction. Pages 83-141 in A. G. Oude Elferink and E. J. Molenaar, editors. The international legal regime of areas beyond national jurisdiction: current and future developments. Martinus Nijhoff, Leiden, The Netherlands.

Berkes, F. 1996. Social systems, ecological systems and property rights. Pages 97-107 in S. S. Hanna, C. Folke, and K.-G. Mähler, editors. Rights to nature: ecological, economic, cultural, and political principles of institutions for the environment. Island Press, Washington, D.C., USA.

Bernstein, L. 1992. Opting out of the legal system: extralegal contractual relations in the diamond industry. Journal of Legal Studies 21(1):115-157. http://dx.doi.org/10.1086/467902

Bishop, P., and V. Jenkins. 2011. Planning and nuisance: revisiting the balance of public and private interests in landuse development. Journal of Environmental Law 23 (2):285-310. http://dx.doi.org/10.1093/jel/eqr002

Department for Communities and Local Government. 2012. National Planning Policy Framework. Department for Communities and Local Government, London, UK. [online] URL: https://www.gov.uk/government/uploads/system/uploads/ attachment_data/file/6077/2116950.pdf.

Ebbesson, J. 2010. The rule of law in governance of complex socio-ecological changes. Global Environmental Change 20 (3):414-422. http://dx.doi.org/10.1016/j.gloenvcha.2009.10.009

Ellickson, R. C. 1973. Alternatives to zoning: covenants, nuisance rules, and fines as land use controls. University of Chicago Law Review 40(4):681-781. [online] URL: http:// digitalcommons.law.yale.edu/fss papers/471/. http://dx.doi. org/10.2307/1599220

Farber, D. A. 1994. Environmental protection as a learning experience. Loyola of Los Angeles Law Review 27(3):791-807. [online] URL: http://digitalcommons.lmu.edu/llr/vol27/iss3/3/.

Fennel, L. A. 2011. Commons, anticommons, semicommons. Pages 35-56 in K. Ayote and H. E. Smith, editors. Research handbook on the economics of property law. Edward Elgar, Cheltenham, UK.

Folke, C. 2006. Resilience: the emergence of a perspective for social-ecological systems analyses. Global Environmental Change 16(3):253-267. http://dx.doi.org/10.1016/j. gloenvcha.2006.04.002

Gilbert, J. 2006. Indigenous peoples' land rights under international law: from victims to actors. Transnational Publishers, Ardsley, New York, USA.

Gunderson, L. H., and C. S. Holling. 2002. Resilience and adaptive cycles. Pages 25-62 in L. H. Gunderson and C. S. Holling, editors. Panarchy: understanding transformations in 
human and natural systems. Island Press, Washington, D.C., USA.

Gunningham, N., and D. Sinclair. 2005. Policy instrument choice and diffuse source pollution. Journal of Environmental Law 17(1):51-81. http://dx.doi.org/10.1093/envlaw/eqi003

Hodgson, S. 2006. Modern water rights: theory and practice. FAO Legislative Study 92. FAO, Rome, Italy. [online] URL: ftp://ftp.fao.org/docrep/fao/010/a0864e/a0864e00.pdf.

Holder, J. 2004. Environmental assessment: the regulation of decision making. Oxford University Press, Oxford, UK.

Holling, C. S. 1973. Resilience and stability of ecological systems. Annual Review of Ecology and Systematics 4:1-23. http://dx.doi.org/10.1146/annurev.es.04.110173.000245

Holling, C. S. 1996. Engineering resilience versus ecological resilience. Pages 31-44 in P. C. Schulze, editor. Engineering within ecological constraints. National Academies Press, Washington, D.C., USA.

Honoré, A. M. 1961. Ownership. Pages 107-147 in A. G. Guest, editor. Oxford essays in jurisprudence: a collaborative work. Oxford University Press, London, UK.

MacCormick, N. 2005. Rhetoric and the rule of law: a theory of legal reasoning. Oxford University Press, Oxford, UK.

McCay, B. J. 2011. Enclosing the fishery commons: from individuals to communities. In D. H. Cole and E. Ostrom, editors. Property in land and other resources. Lincoln Institute of Land Policy, Cambridge, Massachusetts, USA.

McGillivray, D., and J. Wightman. 1997. Private rights, public interests and the environment. Pages 144-160 in T. Hayward and J. O'Neil, editors. Justice, property and the environment: social and legal perspectives. Ashgate, Aldershot, UK.

McHarg, A., B. Barton, A. Bradenbrook, and L. Godden, editors. 2010. Property and the law in energy and natural resources. Oxford University Press. Oxford, UK.

Merrill, T. W., and H. E. Smith. 2000. Optimal standardization in the law of property: the numerous clausus principle. Yale Law Journal 110(1):1-70. [online] URL: http://www. yalelawjournal.org/images/pdfs/450.pdf. http://dx.doi. org/10.2307/797586

Michelman, F. I. 1967. Property, utility, and fairness: comments on the ethical foundations of "just compensation" law. Harvard Law Review 80(6):1165-1258. http://dx.doi. $\underline{\operatorname{org} / 10.2307 / 1339276}$

Montt, S. 2009. State liability in investment treaty arbitration: global constitutional and administrative law in the BIT generation. Hart, Oxford, UK.
Ostrom, E. 1990. Governing the commons: the evolution of institutions for collective action. Cambridge University Press, Cambridge, UK. http://dx.doi.org/10.1017/CBO9780511807763

Rachlinski, J. J. 2000. The psychology of global climate change. University of Illinois Law Review 2000(1):299-319.

Robbins, P. 2000. The rotten institution: corruption in natural resource management. Political Geography 19(4):423-443. http://dx.doi.org/10.1016/S0962-6298(99)00087-6

Roessig, J. M., C. M. Woodley, J. J. Cech, Jr., and L. J. Hansen. 2004. Effects of global climate change on marine and estuarine fishes and fisheries. Reviews in Fish Biology and Fisheries 14 (2):251-275. http://dx.doi.org/10.1007/s11160-004-6749-0

Rose, C. M. 2002. Common property, regulatory property, and environmental protection: comparing community-based management to tradable environmental allowances. Pages 233-257 in E. Ostrom, T. Dietz, N. Dolsak, P. C. Stern, S. Stovich, and E. U. Weber, editors. The drama of the commons. National Academy Press, Washington, D.C., USA.

Ruhl, J. B. 2011. General design principles for resilience and adaptive capacity in legal systems - with applications to climate change adaptation. North Carolina Law Review 89 (5):1373-1401. [online] URL: http://www.nclawreview.org/ documents/89/5/ruhl.pdf.

Smith, H. E. 2000. Semicommon property rights and scattering in the open fields. Journal of Legal Studies 29(1):131-169. http://dx.doi.org/10.1086/468066

Sundström, A. 2012. Corruption and regulatory compliance: experimental findings from South African small-scale fisheries. Marine Policy 36(6):1255-1264. http://dx.doi. org/10.1016/j.marpol.2012.03.013

Tarlock, A. D. 1994. The nonequilibrium paradigm in ecology and the partial unraveling of environmental law. Loyola of Los Angeles Law Review 27(3):1121-1144. [online] URL: http:// digitalcommons.1mu.edu/1lr/vol27/iss3/22/.

Tur, R. H. S. 2001. Defeasibilism. Oxford Journal of Legal Studies 21(2):355-368. http://dx.doi.org/10.1093/ojls/21.2.355

Walker, B., C. S. Holling, S. R. Carpenter, and A. Kinzig. 2004. Resilience, adaptability and transformability in socialecological systems. Ecology and Society 9(2): 5. [online] URL: http://www.ecologyandsociety.org/vol9/iss2/art5/.

Wilson, J. A., J. M. Acheson, M. Metcalfe, and P. Kleban. 1994. Chaos, complexity and community management of fisheries. Marine Policy 18(4):291-305. http://dx.doi. org/10.1016/0308-597X(94)90044-2 